\title{
Digital diplomacy as world disclosure: the case of the COVID-19 pandemic
}

\author{
Corneliu Bjola $^{1}$ (D)
}

Revised: 9 September 2021 / Accepted: 20 September 2021 / Published online: 26 October 2021

(c) The Author(s), under exclusive licence to Springer Nature Limited 2021

\begin{abstract}
The arrival of the COVID-19 pandemic took world diplomats by surprise, partly because of the novelty of the situation and partly because of the speed with which the pandemic travelled around the world. Drawing on the concept of world disclosure, the paper argues that MFAs' digital responses to the pandemic offer an excellent analytical lens for understanding how MFAs have made sense and reacted to the crisis. By examining the tweets posted by German diplomats in the early stage of the pandemic, the paper finds that the German MFAs moved slowly in sensing the nature and severity of the crisis, but it then managed to regroup and formulate a credible strategy to balance its domestic priorities and international responsibilities.
\end{abstract}

Keywords Digital diplomacy · World disclosure · COVID-19

\section{Introduction}

From a digital diplomatic perspective, the COVID-19 pandemic is unmistakably a unique event. The previously similar case, the deadly influenza pandemic that struck the world between 1918 and 20 (also known as the "Spanish flu"), occurred long before the words, "computer", "digital", and "social media" even entered the public vocabulary. While Ministries of Foreign Affairs (MFA) and international organisations have resorted to digital diplomacy in recent years to manage security (Bjola and Papadakis 2020), refugee (Zaiotti 2020) or diplomatic crises (Duncombe 2017), they have experienced nothing comparable to the global scope and systemic consequences that the COVID-19 pandemic has generated.

The pandemic, thus, offers scholars of digital diplomacy a rare opportunity to study MFAs' digital approaches to an unprecedented crisis and in so doing to better understand how MFAs have made sense of the unfolding crisis and how they have responded to it. For space reasons, the current contribution to the forum will focus on a single case study, the German MFA's digital response to the early stage of the pandemic. The selection of the case study takes into account

Corneliu Bjola

corneliu.bjola@qeh.ox.ac.uk

1 Department of International Development, University of Oxford, 3 Mansfield Road, Oxford OX1 3TB, UK the efforts the German MFA has made during the pandemic to muster international support for a coordinated response to the pandemic, especially in Europe. At a time when many governments would bitterly compete against each other for medical supplies and protective equipment, Germany has proved to be one of the few state actors to insist that only a coordinated international response could provide the optimal solution for coping with the pandemic. ${ }^{1}$

Drawing on the concept of "world disclosure" developed by Heidegger and introduced to diplomatic theory by Bjola (2016), the paper will argue that the digital diplomacy has played both an interpretative and instrumental role in the early phase of the pandemic. It has allowed the German MFA to gradually make sense of the scope and severity of the crisis and then to develop a tentative strategy to cope with its domestic and international implications. The argument will be developed in two steps. The first section will introduce the concept of "world disclosure" and explain its relevance for studying digital diplomacy during the pandemic. The second part examines the use of the digital diplomacy by the German MFA as the crisis unfolded during the month of March 2020.

\footnotetext{
$\overline{1}$ For details on the multilateral approach advocated by Germany for addressing the COVID-19 crisis, see German Federal office, "An effective international response by Germany to Covid-19”, June 2020, https://www.auswaertiges-amt.de/blob/2354916/4229a3d433f85ae a39310bb1440a33ac/covid19-data.pdf.
} 


\section{Digital diplomacy as world disclosure}

As discussed in more detail elsewhere (Bjola 2016), Heidegger's conception of world disclosure involves two basic modes of social engagement: affectedness and understanding (Heidegger and Krell 2000). The first mode, affectedness, refers to unreflective states of mind, moods, or sensibilities that we experience as a result of being thrown in the world and finding ourselves in novel and unexpected situations over which we have little control. The shock, anxiety, fear, confusion, or deep sense of duty that diplomats might have experienced during the early stage of the pandemic are, for example, unreflective expressions of their engagement with the complex set of conditions that the pandemic had placed in front of them and for which they had no tested template of action to draw on. The second mode, understanding, refers to the way in which we project ourselves onto possibilities of existence by reflecting on the challenge in from of us and deploying competences to cope with the situation at hand. Understanding is, therefore, a mode of world disclosure that informs the diplomats' "ability-to-be" that is, their ability to adapt to new circumstances, to learn how to assess the implications of the pandemic on their tasks and responsibilities, and to develop strategies and action plans to manage the evolving context.

From an interpretive perspective, MFAs' digital responses help us to grasp how the symbolically pre-structured world of the pandemic has been disclosed to the MFAs. The pandemic gazed at the MFAs in March 2020 and the latter took (unreflexively) note of the gaze. The MFAs' digital activities in the early stage of the pandemic showed how MFAs sensed the crisis that is, how they made sense of what was going on, and how long it took them to overcome the initial stance. From an instrumental perspective, on the other hand, the world was disclosed through MFAs' digital responses. The MFAs, therefore, gazed back at the pandemic and transformed it through their actions. By creating meaning out of the initial state of confusion and chaos, MFA's digital activities changed the context in which they operated. They switched from sensing to reacting to the pandemic: they projected themselves on the existing conditions, decided what directions to pursue, and framed their positions in front of international partners and audiences.

\section{Sensing and reacting to the pandemic: the case of the German MFA}

The empirical analysis draws on a corpus of 115 tweets posted by the German MFA between March 1 and 31, 2020. The themes illustrated in the tweets' texts and images have been grouped in three broad categories: general themes of foreign policy (e.g. relations with other diplomatic actors such as Turkey, Greece, Georgia, the EU, etc.), COVID-specific themes (e.g. repatriation actions, travel alerts, international aid), and COVID "laminations" that is, specific locations, hashtags, actions used by the German MFA to clarify, frame, or reinforce particular COVID-related messages. As shown in Fig. 1 below, retweets of COVID-related messages (in dark blue colour) briefly surfaced on March 2 when Germany, France and UK announced a $€ 5$ million financial aid for Iran to fight the COVID-19 pandemic, ${ }^{2}$ became more frequent after March 13, when the German Foreign Minister, Heiko Mass, convened his first virtual meeting to discuss regional measures to contain the pandemic, ${ }^{3}$ and increased sharply around March 24, when the German MFA announced that the first two Italian patients arrived in German to undergo treatment against the coronavirus. ${ }^{4}$

The timeline of the messages posted by the German MFA reveals in interesting pattern. Despite the presence of clear signals indicating the imminent arrival of the pandemic in Europe, there was little communication about the spread and severity of the pandemic until March 13. It was only a few days after Italy announced the national lockdown on March 8 that the German MFA posted its first COVID-related tweet about Germany exploring options with neighbouring countries to contain the spread of the virus. The frequency of the messages increased from March 13 to March 24 but largely in the same exploratory tone: how Germany in partnership with other countries, the EU, and the international community more broadly (UN, G7, NATO) could take steps to manage the pandemic.

It was roughly around March 24 when the substance and tone of the message visibly changed. The dominant issue switched from trying to make sense of the evolving situation to actively reacting to it by seeking to mobilise resources to facilitate the repatriation of German (and EU) nationals and by demonstrating solidarity with other countries, especially in Europe. This dynamic can be visualised in Fig. 2 below, which shows the evolution of "sensing" vs "reacting" messages. Each COVID-related tweet was placed in one of the two categories using a five-point scale: one or two points were assigned to messages suggesting soft sensing such as exploratory talks with other MFAs about how the deal with the pandemic, while four or five points were assigned to messages indicating robust responses to the pandemic such as concrete measures of providing international assistance.

As Fig. 2 shows, it took the German MFA about twenty days to absorb and process the flow of signals about the nature and magnitude of the crisis. From a world disclosure

\footnotetext{
2 https://twitter.com/GermanyDiplo/status/1234516315760578568.

${ }^{3}$ https://twitter.com/GermanyDiplo/status/1238449787114004481.

${ }^{4}$ https://twitter.com/GermanyDiplo/status/1242412703349706752.
} 


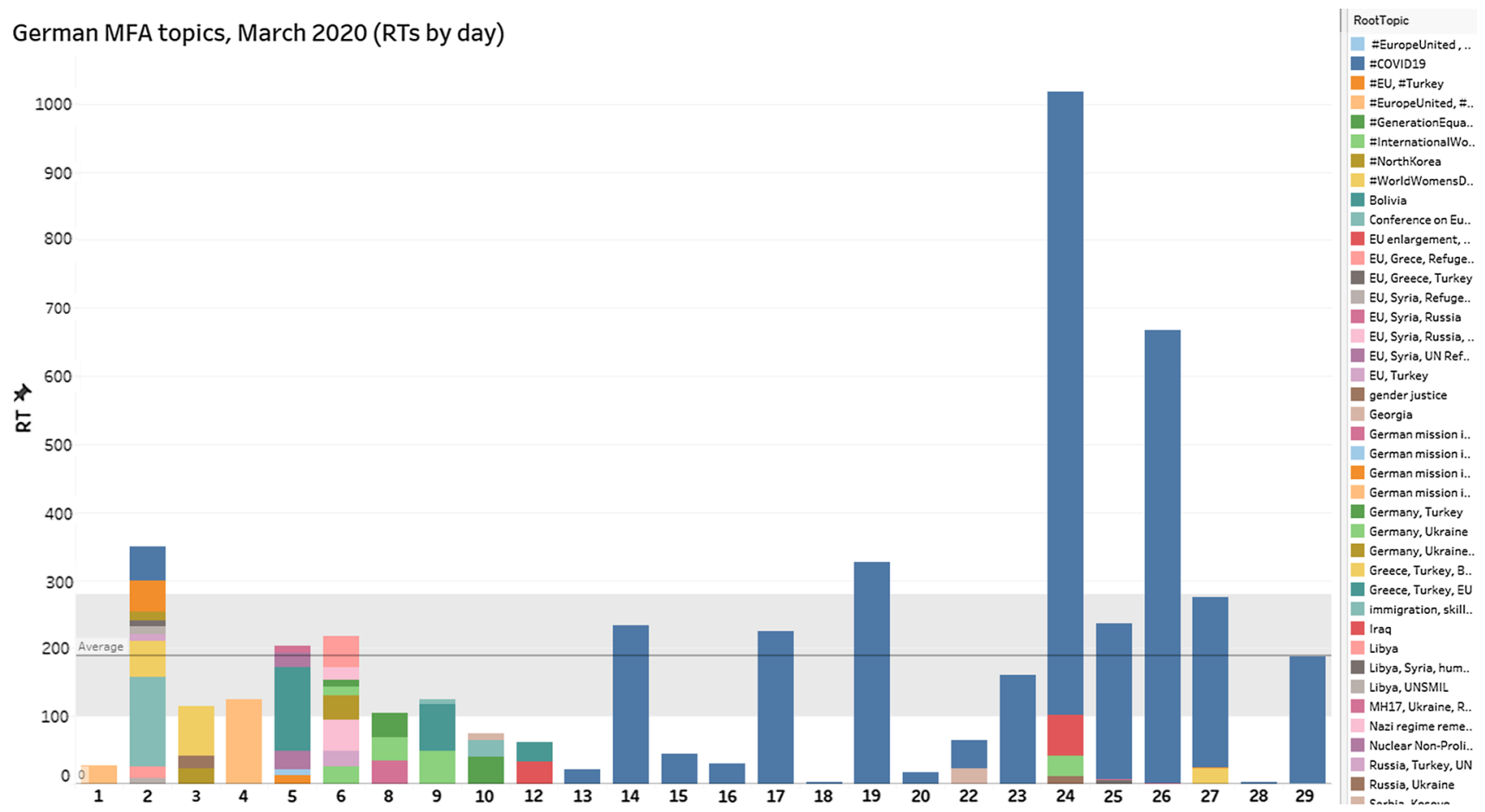

Fig. 1 Timeline of messages posted by the German MFA in the early stage of the pandemic

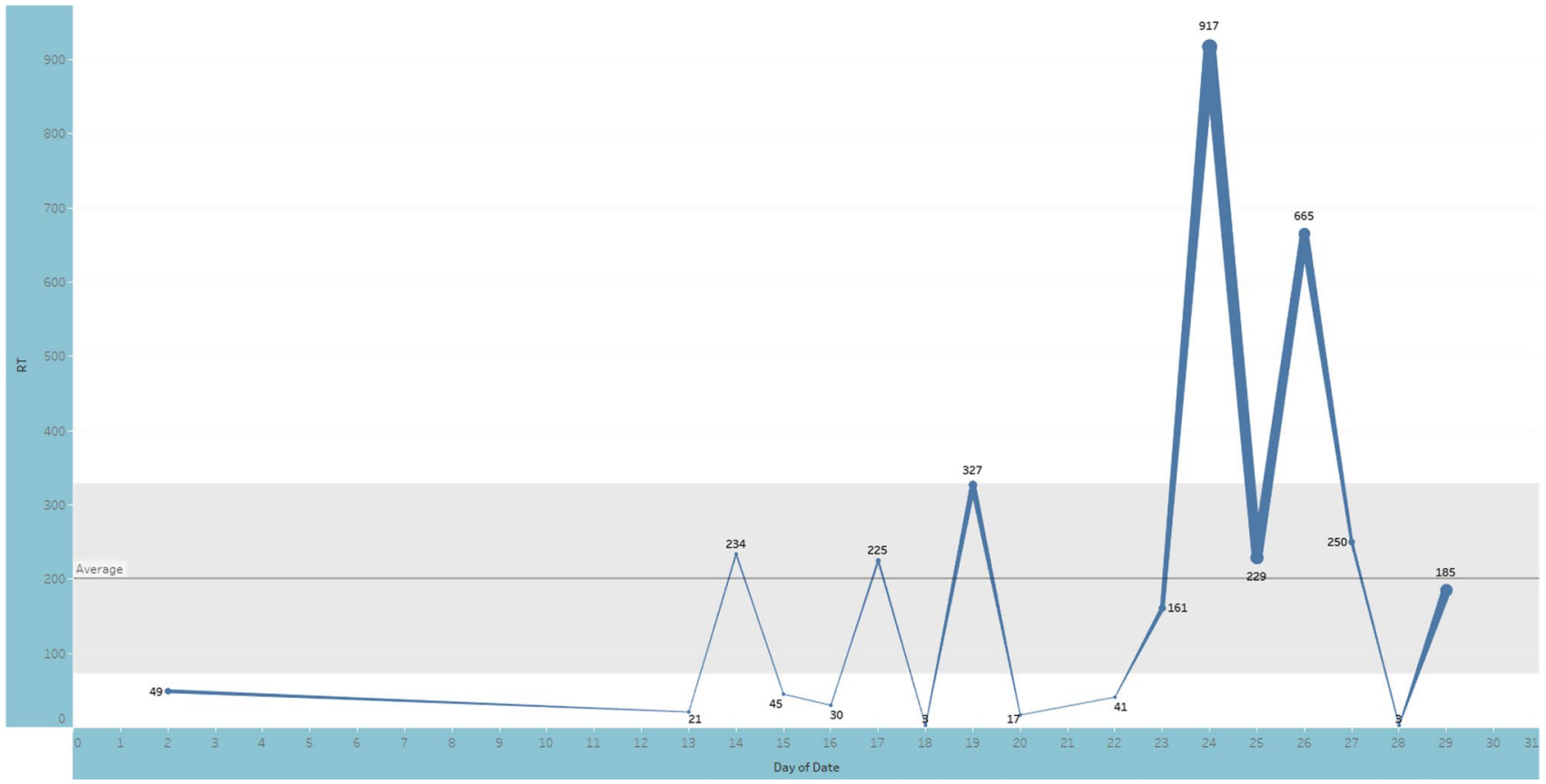

Fig. 2 Timeline of German MFA “sensing” vs "reacting” tweets (RTs per day)

perspective, the period between March 2 and March 24 was all about sense-making. The absence of COVID-related messages before March 13 suggests a lack of concern on the part German MFA about the possibility of the virus to substantially impact the homeland. The prevalence of generic \#COVID19 and \#solidarity hashtags between March 13 and March 24 reveals the increased anxiety experienced by the German MFAs as the virus started to spread 
in the neighbouring countries, but the tone of the message remained exploratory and focused on providing public reassurance. It was basically after March 24 when the reacting mode of world disclosure was full activated as illustrated by the inclusion of more specific laminations in MFAs' tweets, highlighting actions (\#repatriation, \#treatment), positions (\#WeStandTogether, \#EuropeUnited, \#MultilateralismMatters), and places (\#Peru, \#Malta, \#Nepal, \#Uktaine, \#Italy). While the period of sense making was relatively lengthy, the transition from sensing and reacting was rather abrupt, thus, suggesting that the German MFA had a strong capacity to regroup and take action despite the novelty of the crisis.

\section{Conclusion}

Drawing on the concept of world disclosure, the paper has shown that MFAs' digital responses to the pandemic provide an insightful methodological and analytical lens for understanding how MFAs have made sense and reacted to the crisis. To this end, the paper has found that the German MFAs had been rather slow in understanding the nature and severity of the crisis, but it then managed to regroup and act swiftly once the coronavirus started to reach its borders. From a broader perspective of digital crisis management, the paper highlights the critical role that MFA plays in framing and managing online the expectations of the international public during the crisis. The reputation that a country earns for managing a crisis by balancing its national priorities and international responsibilities can have a long-lasting impact on its relationships with other countries once the crisis is over.

\section{References}

Bjola, Corneliu. 2016. Diplomacy as world disclosure: A fractal theory of crisis management. The British Journal of Politics and International Relations 18 (2): 335-350. https://doi.org/10.1111/ 1467-856X.12076.

Bjola, Corneliu, and Krysianna Papadakis. 2020. Digital propaganda, counterpublics and the disruption of the public sphere: The finnish approach to building digital resilience. Cambridge Review of International Affairs 1: 29. https://doi.org/10.1080/09557571. 2019.1704221.

Duncombe, Constance. 2017. Twitter and transformative diplomacy: Social media and Iran-US relations. International Affairs 93 (3): 545-562. https://doi.org/10.1093/ia/iix048.

Heidegger, Martin, and David Farrell C N - Jefferson or Adams Building Reading Rooms B3279.H47; E5 1992 Jefferson or Adams Building Reading Rooms - STORED OFFSITE B3279.H47; E5 1992 Krell. 2000. Basic Writings: From Being and Time (1927) to The Task of Thinking (1964). Rev. and e. London: Routledge.

Zaiotti, Ruben. 2020. "The (UN)Making of International Organisations' Digital Reputation: The European Union, the 'Refugee Crisis,' and Social Media." In Digital Diplomacy and International Organisations: Autonomy, Legitimacy and Contestation, edited by Corneliu Bjola and Ruben Zaiotti, 207-26. Routledge.

Publisher's Note Springer Nature remains neutral with regard to jurisdictional claims in published maps and institutional affiliations.

Corneliu Bjola is Associate Professor in Diplomatic Studies at the University of Oxford and Head of the Oxford Digital Diplomacy Research Group. His recent co-edited volume, "Digital Diplomacy and International Organizations: Autonomy, Legitimacy and Contestation" (Routledge, 2020), examines the broader ramifications of digital technologies on the internal dynamics, multilateral policies, and strategic engagements of international organisations. 